\title{
EDUCAÇÃO FÍSICA NO ENSINO MÉDIO INTEGRADO DA REDE FEDERAL: INTEGRAÇÃO CURRICULAR MEDIADA POR DISTANCIAMENTOS E APROXIMAÇÕES
}

LIDIANE PICOLI LIMA

Instituto Federal do Espírito Santo

E-mail: lidiane.lima@ifes.edu.br

\section{PAULA RAMOS}

Universidade Federal do Rio de Janeiro

E-mail: paularamos.ufrj@gmail.com

\section{ELSA MARIA FERRO RIBEIRO-SILVA}

Universidade de Coimbra

E-mail: elsasilva@fcdef.uc.pt

\section{RESUMO}

O presente artigo objetiva identificar perspectivas e desafios da Educação Física na promoção da integração curricular nos cursos técnicos de nível médio. Realizou-se uma revisão de literatura em produções acadêmico-científicas (artigos, dissertações e teses), com o recorte de tempo entre os anos de 2008 e 2020, por tratar o período desde a constituição do Instituto Federal até a atualidade. Tal estudo se torna relevante ao destacar aproximações e distanciamentos de caráter teórico-prático na Educação Física da rede. Com base nos resultados, pode-se considerar as concepções teóricas e os conteúdos, sugeridos nos documentos institucionais e presentes nas práticas docentes, como fatores relevantes para desenvolver a integração, a depender das ações e objetivos de ensino traçados pelos professores, os quais podem ser consequentes e imbricados com sua formação docente, a estrutura disponível para o trabalho e a metodologia de aula.

\section{PALAVRAS-ChAVE:}

Ensino Médio Integrado; Integração Curricular; Educação Física.

PHYSICAL EDUCATION IN INTEGRATED HIGH SCHOOL OF FEDERAL EDUCATION: CURRICULAR INTEGRATION MEDIATED BY DISTANCES AND APPROACHES

\begin{abstract}
This article aims to identify perspectives and challenges of Physical Education in promoting curricular integration in high school technical courses. A literature review was carried out in academic-scientific productions (articles, dissertations and theses), with a time frame between the years 2008 and 2020, as it deals with the period from the constitution of the Federal Institute to the present day. This study becomes relevant by highlighting theoretical-practical approaches and distances in Physical Education in the network. Based on the results, the theoretical conceptions and contents, suggested in institutional documents and present in teaching practices, can be considered as relevant factors to
\end{abstract}


develop integration, depending on the teaching actions and objectives outlined by the teachers, which may be consequent and intertwined with the teacher training, the structure available for the work and the class methodology.

\section{KEYWORDS:}

Integrated High School; Curricular Integration; Physical Education.

\section{INTRODUÇÃO}

Com a criação do Instituto Federal de Educação, Ciência e Tecnologia pela Rede Federal de Educação Profissional, Científica e Tecnológica no Brasil (Lei n. 11.892, 2008), foi estabelecida a diretriz (Decreto n. 5.194, 2004) que trata da restituição da possibilidade de oferta dos ensinos (médio e técnico) aglutinados, como disposto na Lei de Diretrizes e Bases da Educação Nacional (Lei, n. 9.394, 1996).

De maneira a relacionar as duas possibilidades de ensino, o perfil de formação da Educação Profissional na Rede Federal utiliza da modalidade articulada, tendo como uma de suas possibilidades o Ensino Médio Integrado. A Educação Profissional articula trabalho-ciência-tecnologia-cultura (Lei n. 11.892, 2008). Tal relação busca o desenvolvimento nacional por meio da formação de futuros trabalhadores; ampliação do sentido de cidadania e os conhecimentos sobre a ciência. Assim, a Educação Profissional tende a criar condições de formação social, cultural, de ciência e tecnologia.

As Diretrizes Curriculares Nacionais para a Educação Profissional Técnica de Nível Médio, do Ministério da Educação (2012), em seus princípios norteadores, pontua que o currículo destas instituições deve ser planejado com o intuito de promover a formação para o trabalho, além da formação integral dos discentes, contribuindo para o desenvolvimento, das suas dimensões humana, reflexiva e crítica, da capacidade criativa e de tomada de decisão frente às necessidades sociais e às exigências contemporâneas. 
Dessa maneira, a formação pensada pela Rede Federal tenta superar a perspectiva de dualidade entre Educação Profissional e Ensino Médio, no caminho para uma formação unitária e politécnica. Podemos aproximar esse entendimento ao de educação orgânica de Frigotto (2010, p. 37), quando compreende que [...] trata-se de uma educação não dualista, que articule cultura, conhecimento, tecnologia e trabalho como direito de todos e condição da cidadania e democracia efetivas.

Moura (2010) expõe que essa visão de Educação Profissional objetiva uma integralidade dos conhecimentos científicos, historicamente produzidos, com os saberes adicionais da formação profissional. Tais condições permitem superar o sistema fragmentado de educação, que prevaleceu ao longo de décadas e que era mobilizado apenas pelo domínio do ofício (MANFREDI, 2017). Pode, ainda, ultrapassar o sentido de formação restrita às necessidades do mercado e contribuir para o fortalecimento da cidadania e democratização do conhecimento (PACHECO et al., 2012).

Busca-se, assim, uma formação integral dos alunos com vistas a diminuir o dualismo existente não apenas em nível de oferta universal, mas também na discrepância entre cultura geral e técnica, formação instrumental e acadêmica.

Entre as diferentes formas de organização curricular, o currículo disciplinar e a integração curricular podem não ser contrários entre si (LOPES, 2008). O currículo integrado se faz presente por meio do diálogo institucional, que coloca em evidência os conhecimentos escolares e docentes, sem perder de vista os processos inerentes à pessoa (QUINTINO; ROSA, 2005).

No tocante às propostas curriculares, as afirmações que ressaltam a integração curricular entre ensino médio e técnico são recorrentes. Porém, nas experiências cotidianas, não são raras as dificuldades enfrentadas de formalizações tangíveis. A fragmentação curricular é frequente, ao passar por diferentes esferas do currículo, 
como no interior das disciplinas e na sua relação com outros componentes escolares (CORDÃO \& MORAIS, 2017).

Especificamente sobre a disciplina de Educação Física, no Ensino Médio Integrado, existe a preocupação de que seu desenvolvimento seja predominantemente direcionado ao atendimento do mercado de trabalho, menosprezando os preceitos sociais, políticos e econômicos a ela interligados, o que dificulta, em muitas situações, a formação humana e cidadã (SILVA et al., 2016).

Alguns autores que estudaram as contribuições da Educação Física nos cursos técnicos de nível médio da Rede Federal destacam a escassez de outros estudos sobre o assunto (GASPAROTTO \& NAVARRO, 2017; MEDEIROS et al., 2019), além das dificuldades em trabalhar com uma proposta de integração.

Como forma a ampliar a discussão sobre o tema, este artigo é composto de uma revisão de literatura que teve como objetivo identificar as perspectivas e os desafios da Educação Física escolar nos cursos técnicos de nível médio, no prisma da integração curricular. Ao dialogarmos com as produções apresentadas pela revisão, torna-se oportuno conhecer as iniciativas e/ou reflexões do processo de ensino-aprendizagem da Educação Física na Rede Federal de Educação, Ciência e Tecnologia.

O levantamento bibliográfico ofereceu um material que permitiu destacar as aproximações e distanciamentos sobre a teoria e a prática da Educação Física com base nos currículos analisados, nas ações docentes e sua relação com a formação do Ensino Médio Integrado.

\section{METOdOLOGIA}

Para realizar a revisão da literatura, buscamos trabalhos acadêmicos (artigos, dissertações e teses), cujo objeto de pesquisa fosse a EF no EMI, disponíveis nas bases de dados Google Acadêmico, Portal de Periódicos Capes e Biblioteca Digital de Teses e 
Dissertações (BDTD). Do ponto de vista metodológico, definimos os seguintes passos: selecionamos trabalhos de caráter empírico e teórico - com análise de Projetos Políticos de Curso (PPCs) e/ou com trabalhos de campo e/ou entrevistas - pelas relações estabelecidas com a prática de ensino em Educação Física; textos disponíveis em português, inglês e espanhol; em relação ao recorte temporal, levamos em conta o ano de criação dos Institutos Federais (BRASIL, 2008) e, portanto, assumimos como foco o período de publicação entre 2008 e 2020 (fevereiro); foram excluídos os trabalhos que não retratavam a Rede Federal de ensino ou que enfatizavam o Ensino Médio Integrado ao Ensino Técnico na modalidade Proeja (Programa de Integração de Educação Profissional com a Educação Básica, na modalidade de Jovens e Adultos) ou que tratavam de outros conhecimentos específicos com base no movimento humano, por exemplo, disciplinas curriculares obrigatórias como a dança. Os estudos que adotaram apenas os discentes como sujeitos da pesquisa não foram englobados em nosso registro, bem como as publicações duplicadas.

Além desses passos, em todas as plataformas, foram adotadas as seguintes palavras-chave: a) educação física, b) ensino médio integrado e c) rede federal. Para trazer maior rigor no rastreio, empregamos os operadores booleanos: "educação física" AND "ensino médio integrado" AND "rede federal". Realizamos a leitura dos títulos e resumo dos trabalhos e, quando necessário, recorremos a análise do texto completo (no caso dos artigos) - ou partes do texto (no caso das dissertações e teses).

Na base Google Acadêmico, reunimos um total de 973 trabalhos, dos quais, 15 foram selecionados. Na Plataforma Periódicos Capes, foram reunidos 8 trabalhos, dos quais, excluindo-se os repetidos, nenhum foi selecionado. Na Biblioteca Digital de Teses e Dissertações, foram encontrados 3 trabalhos, dos quais nenhum foi selecionado. A organização do corpus de análise pode ser observada no Quadro 1, a seguir: 
Quadro 1: Etapas do levantamento bibliográfico e material selecionado para análise sobre as práticas da Educação Física no ensino médio integrado ao ensino técnico. Fonte: autoria própria.

\begin{tabular}{|c|c|c|c|}
\hline $\begin{array}{l}\text { Recorte Temporal } \\
\quad(2008-2020)\end{array}$ & $\begin{array}{l}\text { Trabalhos } \\
\text { Encontrados }\end{array}$ & $\begin{array}{l}\text { Trabalhos } \\
\text { selecionados }\end{array}$ & Tipos de trabalhos \\
\hline Google Acadêmico & 973 & 15 & $\begin{array}{l}5 \text { ARTIGOS } \\
6 \text { DISSERTAÇÕES } \\
4 \text { TESES }\end{array}$ \\
\hline Capes & 8 & 1 & ARTIGO \\
\hline $\begin{array}{c}\text { Biblioteca Digital de Teses e } \\
\text { Dissertações - BDTD }\end{array}$ & 3 & 0 & - \\
\hline TOTAL & & $15^{*}$ & PUBLICAÇÕES \\
\hline Descritores utilizados & \multicolumn{3}{|c|}{$\begin{array}{l}\text { "Educação Física" AND } \\
\text { "ensino médio integrado" AND } \\
\text { "Rede Federal" }\end{array}$} \\
\hline$*$ & \multicolumn{3}{|c|}{$\begin{array}{l}\text { O artigo encontrado no Periódico Capes também aparece na } \\
\text { plataforma Google Acadêmico razão pela qual não é } \\
\text { contabilizado na seleção total de trabalhos. }\end{array}$} \\
\hline
\end{tabular}

Ao analisarmos o corpus dos trabalhos, buscamos identificar, na literatura, os desafios e as perspectivas do processo de integração curricular da Educação Física com o ensino técnico de nível médio. Dessa forma, primeiramente, como desafios, foram analisadas as principais problemáticas enfrentadas pelos autores sobre a Educação Física no Ensino Médio Integrado. Em momento posterior, ao que corresponde às perspectivas, pontuamos os planejamentos, ações e possibilidades/propostas nas produções para se efetivarem as práticas de ensino da Educação Física que superassem as dificuldades enfrentadas.

Realizamos a leitura, na íntegra, dos artigos selecionados. No que se refere às dissertações e teses, pela extensão e característica dos textos, adotamos a leitura das seções em que consideramos mais propensas a encontrarmos as informações de busca: resumo, introdução, resultados e considerações finais. 
Para o tratamento dos elementos encontrados, fizemos uso da análise de conteúdo (BARDIN, 1977/2018). Elencamos categorias e subcategorias, descritas nas próximas seções. Chamamos a atenção para a existência de publicações que se inserem em mais de uma categoria e/ou subcategoria.

\section{RESULTADOS E DISCUSSÃO}

Em alusão aos artigos, constata-se a presença de três periódicos voltados para a área de Educação Física, um direcionado ao tema da Educação e um vinculado a um Instituto Federal, que divulga artigos orientados para temas interdisciplinares. Além disso, todos os trabalhos retratam, em seus objetivos, a tentativa de pensar o ensino da Educação Física. Os 15 trabalhos selecionados para a análise, distribuídos em artigos, dissertações e teses são apresentados no Quadro 2.

Quadro 2: Publicações acadêmico-científica sobre a Educação Física no ensino médio integrado ao ensino técnico dos institutos federais do país. Fonte: autoria própria.

\begin{tabular}{|c|c|c|c|}
\hline AUTOR & $\begin{array}{l}\text { 1. TÍTULO } \\
\text { 2. OBJETIVO }\end{array}$ & $\begin{array}{l}\text { DOCUMENTO* } \\
\text { AMOSTRA }\end{array}$ & $\begin{array}{l}\text { PRINCIPAIS RESULTADOS SOBRE } \\
\text { ENSINO MÉDIO INTEGRADO }\end{array}$ \\
\hline \multicolumn{4}{|c|}{ ARTIGOS } \\
\hline 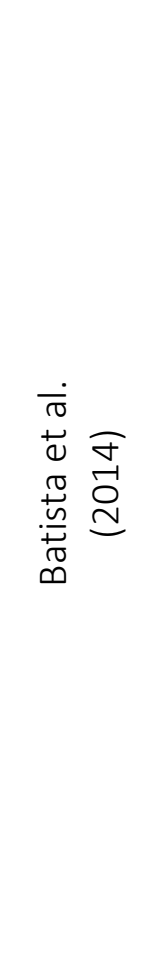 & 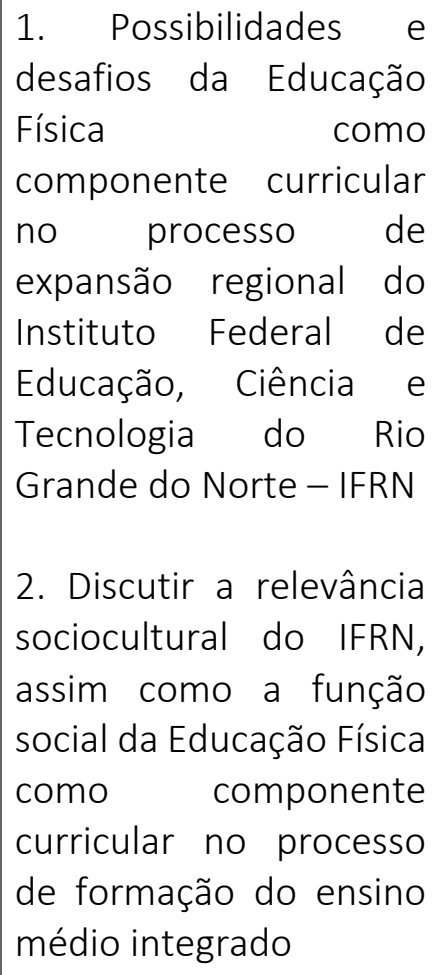 & 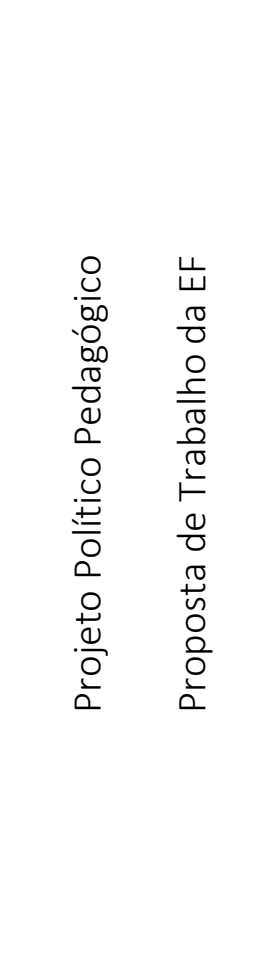 & $\begin{array}{l}\text { Ações e práticas pedagógicas } \\
\text { contextualizadas com a função social e a } \\
\text { formação integrada na instituição, à } \\
\text { medida em que organiza conteúdos } \\
\text { adotando a concepção da cultura de } \\
\text { movimento, em diálogo com os } \\
\text { pressupostos teórico-metodológicos } \\
\text { norteadores da formação humana integral }\end{array}$ \\
\hline
\end{tabular}




\begin{tabular}{|c|c|c|c|c|}
\hline AUTOR & $\begin{array}{l}\text { 1. TÍTULO } \\
\text { 2. OBJETIVO }\end{array}$ & \multicolumn{2}{|c|}{$\begin{array}{l}\text { DOCUMENTO* } \\
\text { AMOSTRA }\end{array}$} & $\begin{array}{l}\text { PRINCIPAIS RESULTADOS SOBRE } \\
\text { ENSINO MÉDIO INTEGRADO }\end{array}$ \\
\hline 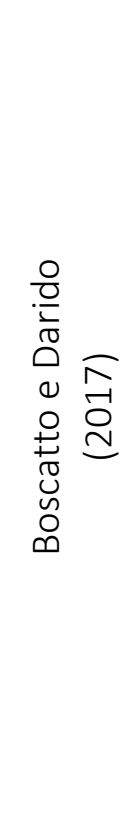 & $\begin{array}{l}\text { 1. A Educação Física no } \\
\text { ensino médio integrado } \\
\text { a Educação Profissional } \\
\text { e tecnológica: } \\
\text { percepções, curriculares } \\
\text { 2. Identificar como os } \\
\text { professores entendem a } \\
\text { finalidade da Educação } \\
\text { Física e quais conteúdos } \\
\text { predominam para o } \\
\text { ensino médio integrado } \\
\text { à Educação Profissional } \\
\text { em um Instituto Federal } \\
\text { localizado no estado de } \\
\text { Santa Catarina }\end{array}$ & 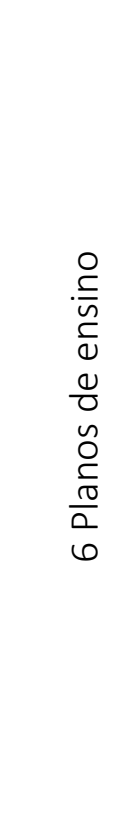 & 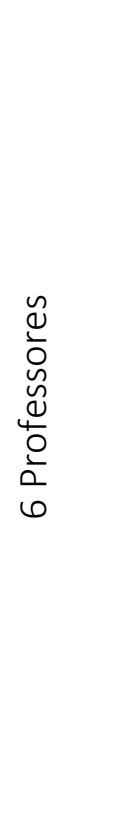 & $\begin{array}{l}\text { Identificaram três blocos de conteúdos } \\
\text { utilizados em aula (esportes, prática } \\
\text { corporais relacionadas à saúde, demais } \\
\text { elementos da cultura corporal), cuja } \\
\text { finalidade direcionava para a promoção da } \\
\text { saúde e a compreensão crítica dos } \\
\text { conhecimentos. Entretanto, os } \\
\text { professores (nas entrevistas) não } \\
\text { aprofundam como se dá, em suas práticas, } \\
\text { a ocorrência e a relação com os aspectos } \\
\text { da integração curricular. }\end{array}$ \\
\hline 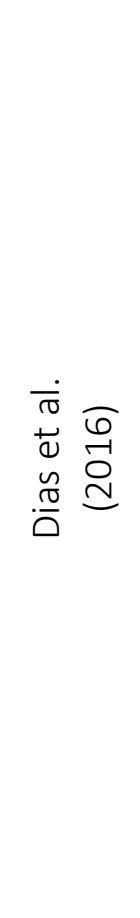 & $\begin{array}{l}\text { 1. Pedagogia histórico- } \\
\text { crítica, cultura corporal, } \\
\text { saúde e atividade física: } \\
\text { aspectos teóricos e } \\
\text { metodológicos para o } \\
\text { ensino médio } \\
\text { 2. Apresentar um plano } \\
\text { de unidade realizado nas } \\
\text { aulas de Educação Física } \\
\text { com turmas do ensino } \\
\text { médio integrado de uma } \\
\text { instituição federal de } \\
\text { ensino, considerando a } \\
\text { referência teórico- } \\
\text { metodológica do } \\
\text { materialismo histórico } \\
\text { dialético }\end{array}$ & $\begin{array}{l}\frac{0}{0} \\
\frac{0}{0} \\
\frac{0}{1} \\
\frac{0}{5} \\
0 \\
0 \\
0 \\
\frac{0}{\frac{1}{0}} \\
\frac{0}{\alpha}\end{array}$ & 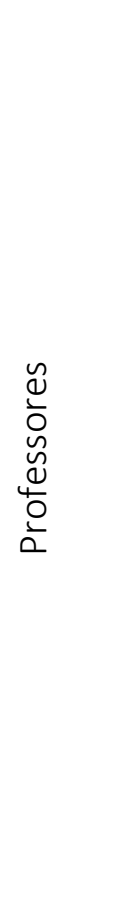 & $\begin{array}{l}\text { Apresentaram como perspectivas } \\
\text { proposta de: atividade física, saúde e } \\
\text { influência da mídia, com base em um } \\
\text { processo de relação crítica. }\end{array}$ \\
\hline
\end{tabular}




\begin{tabular}{|c|c|c|c|}
\hline AUTOR & $\begin{array}{l}\text { 1. TÍTULO } \\
\text { 2. OBJETIVO }\end{array}$ & $\begin{array}{l}\text { DOCUMENTO* } \\
\text { AMOSTRA }\end{array}$ & $\begin{array}{l}\text { PRINCIPAIS RESULTADOS SOBRE } \\
\text { ENSINO MÉDIO INTEGRADO }\end{array}$ \\
\hline 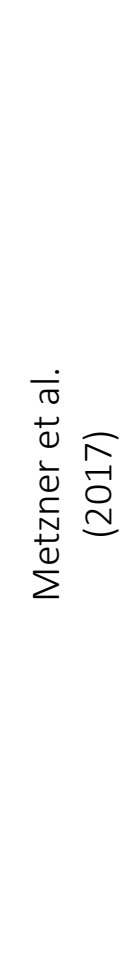 & $\begin{array}{l}\text { 1. Contribuição da } \\
\text { Educação Física para o } \\
\text { ensino médio: estudo a } \\
\text { partir da prática docente } \\
\text { de professores de } \\
\text { Institutos Federais } \\
\text { 2. Identificar e analisar } \\
\text { elementos que } \\
\text { contribuem para a } \\
\text { consolidação } \\
\text { Educação Física no } \\
\text { ensino médio integrado } \\
\text { ao ensino técnico a } \\
\text { partir de diários de aulas } \\
\text { e registros de atividades } \\
\text { coordenadas por } \\
\text { professores de, durante } \\
\text { um ano letivo }\end{array}$ & 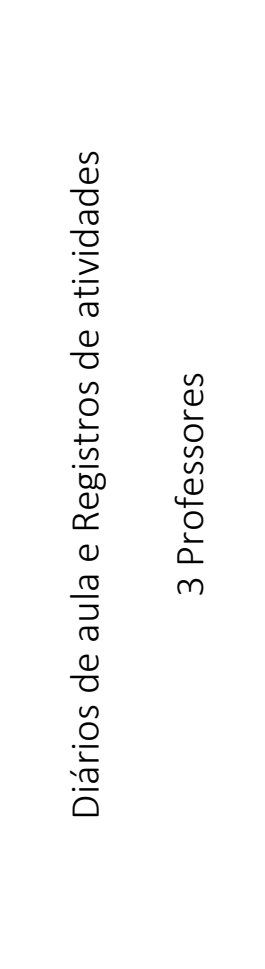 & $\begin{array}{l}\text { Apontam algumas propostas de integração } \\
\text { curricular adotando como foco de análise, } \\
\text { a caracterização da Educação Física, as } \\
\text { ações pedagógicas de ensino e os projetos. }\end{array}$ \\
\hline 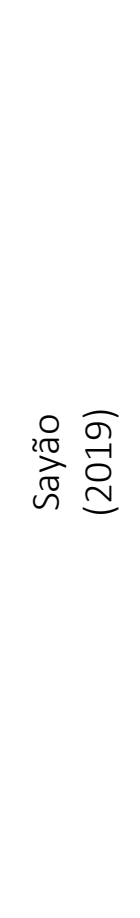 & $\begin{array}{l}\text { 1. A Educação Física na } \\
\text { Educação Profissional: } \\
\text { sentidos em disputa no } \\
\text { Instituto Federal de } \\
\text { Educação, Ciência e } \\
\text { Tecnologia do Rio de } \\
\text { Janeiro - IFRJ } \\
\text { 2. Traçar um panorama } \\
\text { da atuação da Educação } \\
\text { Física na Educação } \\
\text { Profissional partindo da } \\
\text { premissa de que não há } \\
\text { uma única maneira de } \\
\text { conceber esta atuação, } \\
\text { mas uma diversidade de } \\
\text { possibilidades em } \\
\text { disputa }\end{array}$ & 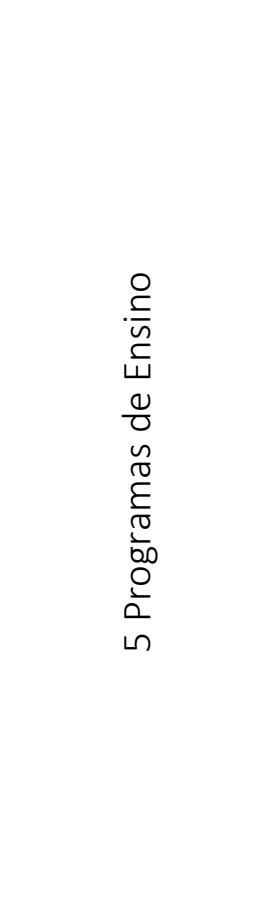 & $\begin{array}{l}\text { Verificou nesse processo um } \\
\text { deslocamento no currículo, de acordo com } \\
\text { a inserção dos novos professores, que } \\
\text { adaptaram seus programas de ensino na } \\
\text { perspectiva de adotar os aspectos } \\
\text { culturais e sociais nos objetivos, } \\
\text { superando a prática da condição restrita } \\
\text { ao biologicismo e se aproximando da } \\
\text { integração curricular, ao trazer os } \\
\text { princípios humanísticos para a formação } \\
\text { do aluno. }\end{array}$ \\
\hline \multicolumn{4}{|c|}{ DISSERTAÇÕES } \\
\hline
\end{tabular}




\begin{tabular}{|c|c|c|c|c|}
\hline AUTOR & $\begin{array}{l}\text { 1. TÍTULO } \\
\text { 2. OBJETIVO }\end{array}$ & \multicolumn{2}{|c|}{$\begin{array}{l}\text { DOCUMENTO* } \\
\text { AMOSTRA }\end{array}$} & $\begin{array}{l}\text { PRINCIPAIS RESULTADOS SOBRE } \\
\text { ENSINO MÉDIO INTEGRADO }\end{array}$ \\
\hline 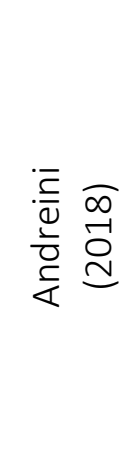 & $\begin{array}{l}\text { 1. O ensino da Educação } \\
\text { Física no Instituto } \\
\text { Federal de São Paulo } \\
\text { 2. Analisar o ensino da } \\
\text { Educação Física no IFSP }\end{array}$ & 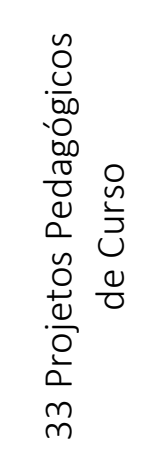 & 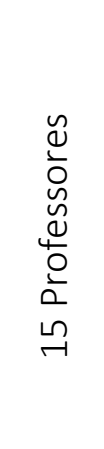 & $\begin{array}{l}\text { Evidência de concepções teóricas que } \\
\text { conduzem para a formação do } \\
\text { conhecimento crítico e do cidadão } \\
\text { consciente à problematização das } \\
\text { questões sociais, enquanto referenciais. } \\
\text { Tais iniciativas se dão por meio de } \\
\text { conteúdos inerentes ao âmbito da cultura } \\
\text { corporal e relacionados a saúde }\end{array}$ \\
\hline 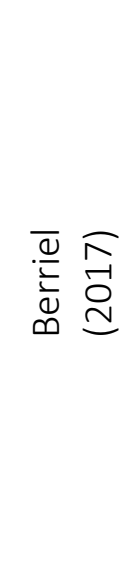 & $\begin{array}{l}\text { 1. O professor de } \\
\text { Educação Física na } \\
\text { Educação Técnica } \\
\text { Agrícola do Colégio } \\
\text { Técnico da UFRRJ } \\
\text { 2. Estudar o professor de } \\
\text { Educação Física na } \\
\text { educação técnica } \\
\text { agrícola do Colégio } \\
\text { Técnico da UFRRJ }\end{array}$ & 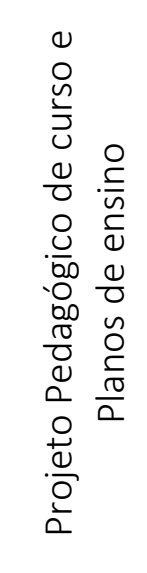 & 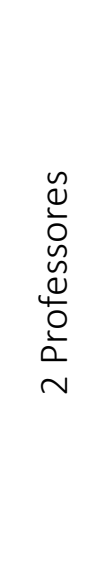 & $\begin{array}{l}\text { Diante das dificuldades de estrutura física, } \\
\text { por exemplo, os docentes (re)criam } \\
\text { formas de aulas e diversificam os } \\
\text { conteúdos pautados em pensamentos } \\
\text { teóricas que ultrapassam as visões mais } \\
\text { tradicionais, em direção a formação de } \\
\text { indivíduos mais críticos e conscientes }\end{array}$ \\
\hline 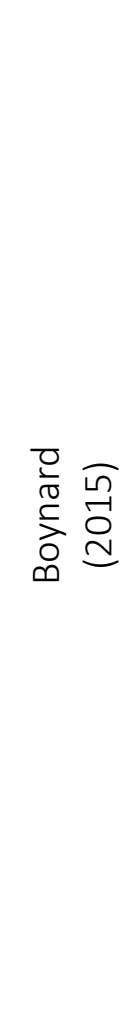 & $\begin{array}{l}\text { 1. A prática pedagógica } \\
\text { do docente da disciplina } \\
\text { Educação Física no } \\
\text { Instituto Federal } \\
\text { Fluminense campus } \\
\text { Centro: desvendando } \\
\text { saberes e práticas } \\
\text { 2. Conhecer os saberese } \\
\text { as práticas dos docentes } \\
\text { da disciplina; analisar as } \\
\text { limitações pelos } \\
\text { potencialidades } \\
\text { vivenciadas } \\
\text { professores no processo } \\
\text { ensino-aprendizagem e } \\
\text { propor atividades } \\
\text { didático-pedagógicas, } \\
\text { priorizando as } \\
\text { metodologias ativas }\end{array}$ & 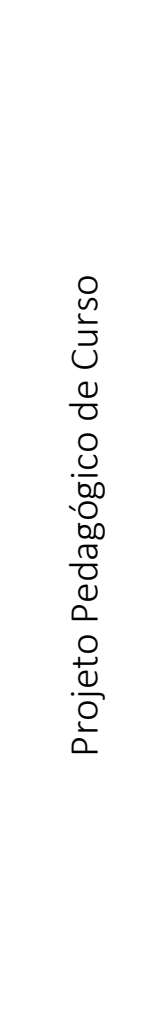 & 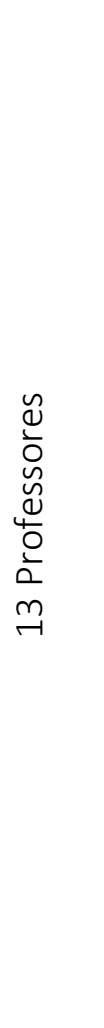 & $\begin{array}{l}\text { O desafio de identificar critérios para } \\
\text { reconhecer inovações e espaços para o } \\
\text { pensar e o fazer reflexivos e } \\
\text { instrumentalizar as concepções inerentes } \\
\text { a uma proposta de ensino médio } \\
\text { integrada. }\end{array}$ \\
\hline
\end{tabular}




\begin{tabular}{|c|c|c|c|c|}
\hline AUTOR & $\begin{array}{l}\text { 1. TÍTULO } \\
\text { 2. OBJETIVO }\end{array}$ & \multicolumn{2}{|c|}{$\begin{array}{l}\text { DOCUMENTO* } \\
\text { AMOSTRA }\end{array}$} & $\begin{array}{l}\text { PRINCIPAIS RESULTADOS SOBRE } \\
\text { ENSINO MÉDIO INTEGRADO }\end{array}$ \\
\hline 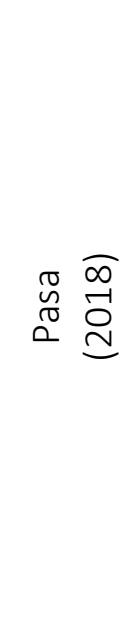 & $\begin{array}{l}\text { 1. A contribuição da } \\
\text { disciplina de Educação } \\
\text { Física para a formação } \\
\text { integral dos alunos } \\
\text { 2. Conhecer a } \\
\text { contribuição } \\
\text { disciplina de Educação } \\
\text { Física para uma } \\
\text { formação integral }\end{array}$ & 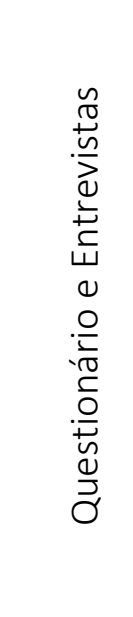 & 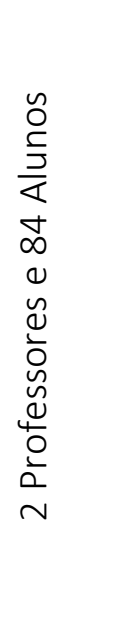 & $\begin{array}{l}\text { Destaca a importância desse componente } \\
\text { curricular na medida em que serve como } \\
\text { uma janela para ver o mundo, pelo olhar } \\
\text { da perspectiva que relaciona } \\
\text { historicamente os temas da Educação } \\
\text { Física (como jogo, a dança, o esporte, as } \\
\text { práticas corporais junto à natureza, a } \\
\text { dança e as lutas), em suas diferentes } \\
\text { dimensões de ensino, e permite as } \\
\text { manifestações individuais dos alunos, } \\
\text { respeitando suas diferenças e } \\
\text { contribuindo para o seu papel formativo. }\end{array}$ \\
\hline 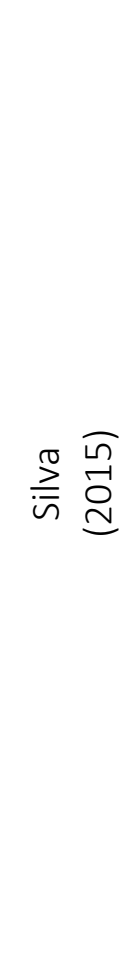 & $\begin{array}{l}\text { 1. A Educação Física no } \\
\text { contexto dos cursos de } \\
\text { Educação Profissional } \\
\text { técnica de nível médio } \\
\text { integrado do Instituto } \\
\text { Federal de Educação, } \\
\text { Ciência e Tecnologia do } \\
\text { Mato Grosso do Sul } \\
\text { 2. Analisar a disciplina } \\
\text { Educação Física no } \\
\text { contexto dos cursos de } \\
\text { Educação Profissional } \\
\text { técnica de nível médio } \\
\text { integrado do Instituto } \\
\text { Federal de Educação, } \\
\text { Ciência e Tecnologia de } \\
\text { Mato Grosso do Sul - } \\
\text { IFMS }\end{array}$ & 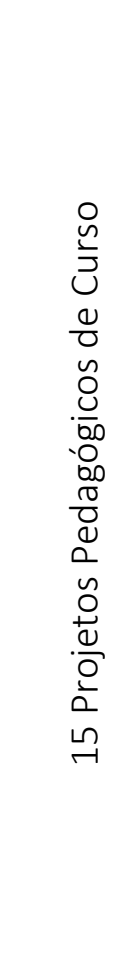 & 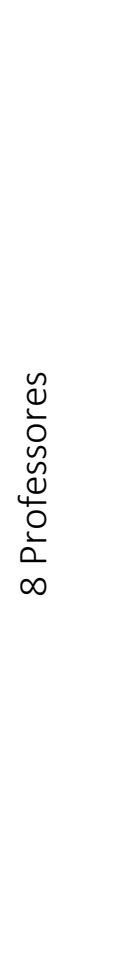 & $\begin{array}{l}\text { Para consolidar a Educação Profissional } \\
\text { técnica de nível médio integrada, a } \\
\text { estrutura dos projetos de curso e dos } \\
\text { próprios cursos foram organizados em } \\
\text { conhecimentos gerais (ensino médio) e } \\
\text { específicos (formação técnica). Outra } \\
\text { perspectiva que podem ser articuladas a } \\
\text { mobilizar instrumentos didáticos de } \\
\text { integração são as ações disponíveis para os } \\
\text { alunos durante o processo de formação } \\
\text { acadêmica, como: projetos de pesquisa, } \\
\text { extensão, estágio curricular obrigatório e } \\
\text { trabalho de conclusão de curso. }\end{array}$ \\
\hline
\end{tabular}




\begin{tabular}{|c|c|c|c|}
\hline AUTOR & $\begin{array}{l}\text { 1. TÍTULO } \\
\text { 2. OBJETIVO }\end{array}$ & $\begin{array}{l}\text { DOCUMENTO* } \\
\text { AMOSTRA }\end{array}$ & $\begin{array}{l}\text { PRINCIPAIS RESULTADOS SOBRE } \\
\text { ENSINO MÉDIO INTEGRADO }\end{array}$ \\
\hline 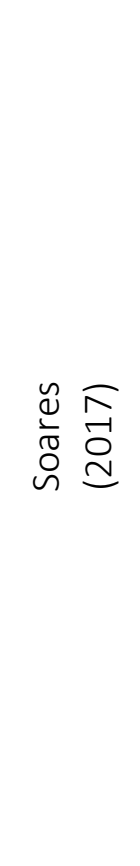 & $\begin{array}{l}\text { 1. O currículo prescrito } \\
\text { da Educação Física num } \\
\text { contexto de Ensino } \\
\text { Médio Integrado } \\
\text { 2. Compreender o lugar } \\
\text { da disciplina no currículo } \\
\text { dos cursos técnicos } \\
\text { integrados dessa } \\
\text { instituição, identificando } \\
\text { os focos de ensino } \\
\text { propostos e as } \\
\text { concepções de ensino } \\
\text { da Educação Física } \\
\text { presentes nos planos }\end{array}$ & 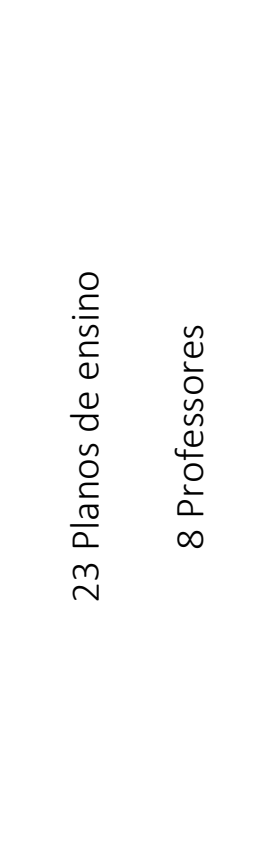 & $\begin{array}{l}\text { Mencionou o papel da disciplina, } \\
\text { defendido pelos professores. Também } \\
\text { aprofundou as possibilidades conceituais e } \\
\text { de conteúdos, diretamente interligadas às } \\
\text { tendências e abordagens, nas quais os } \\
\text { professores acreditam, bem como são } \\
\text { oferecidas pela instituição, de acordo com } \\
\text { o quadro docente, estrutura, carga horária } \\
\text { e curso. Ao destacar os focos de ensino } \\
\text { defendidos pelos docentes, a autora } \\
\text { apresenta os conteúdos ligados ao corpo, } \\
\text { esportes e saúde, dando valor para a } \\
\text { relevância social com a discussão da } \\
\text { diferença, diversidade, tecnologia e } \\
\text { contexto histórico, por meio dos } \\
\text { elementos da cultura corporal de } \\
\text { movimento. }\end{array}$ \\
\hline \multicolumn{4}{|c|}{ TESES } \\
\hline in & $\begin{array}{l}\text { 1. Currículo do Ensino } \\
\text { Médio Integrado do } \\
\text { IFMG: a partitura, a } \\
\text { polifonia e os solos da } \\
\text { Educação Física } \\
\text { 2. Analisar o currículo do } \\
\text { Ensino Médio Integrado } \\
\text { (EMI) do IFMG, suas } \\
\text { conexões com a } \\
\text { educação em tempo } \\
\text { integral e com a } \\
\text { construção curricular do } \\
\text { componente Educação } \\
\text { Física (EF) }\end{array}$ & 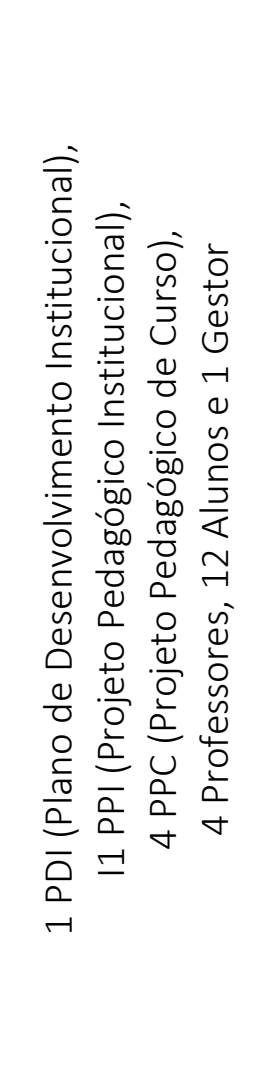 & $\begin{array}{l}\text { Em sua maioria, os documentos não } \\
\text { colaboram para a formação da integração } \\
\text { curricular, por não contemplar as múltiplas } \\
\text { dimensões formativas e não exprimir a } \\
\text { construção coletiva. Há um desalinho nos } \\
\text { discursos neoliberal e as propostas de } \\
\text { Educação Física, de base nas concepções } \\
\text { críticas e pós-críticas. Entretanto, a autora } \\
\text { sinaliza a possibilidade de, no espaço } \\
\text { democrático e coletivo da escola, existir a } \\
\text { construção de planos de ensino que } \\
\text { extrapolem as contingências dos PPC's e } \\
\text { trabalhem na perspectiva de um currículo } \\
\text { em ação, no movimento integrado. Nessa } \\
\text { sequência, como proposta de trazer maior } \\
\text { legitimidade e reconhecimento para a } \\
\text { área, a autora relata as ações de } \\
\text { (re)construção do trabalho pedagógico } \\
\text { amparado pelo viés: das teorias críticas, da } \\
\text { implantação dos documentos legais e da } \\
\text { cultura corporal. }\end{array}$ \\
\hline
\end{tabular}




\begin{tabular}{|c|c|c|c|c|}
\hline AUTOR & $\begin{array}{l}\text { 1. TÍTULO } \\
\text { 2. OBJETIVO }\end{array}$ & \multicolumn{2}{|c|}{$\begin{array}{l}\text { DOCUMENTO* } \\
\text { AMOSTRA }\end{array}$} & $\begin{array}{l}\text { PRINCIPAIS RESULTADOS SOBRE } \\
\text { ENSINO MÉDIO INTEGRADO }\end{array}$ \\
\hline 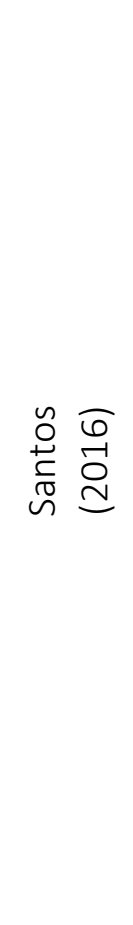 & $\begin{array}{l}\text { 1. A Educação Física no } \\
\text { currículo integrado do } \\
\text { IFBA: realidade e } \\
\text { possibilidades } \\
\text { 2. Compreender e } \\
\text { analisar as contradições, } \\
\text { limites e possibilidades } \\
\text { na implantação do } \\
\text { Currículo Integrado e as } \\
\text { implicações no trabalho } \\
\text { pedagógico da Educação } \\
\text { Física, tendo como base } \\
\text { o Projeto Pedagógico } \\
\text { Institucional do IFBA }\end{array}$ & 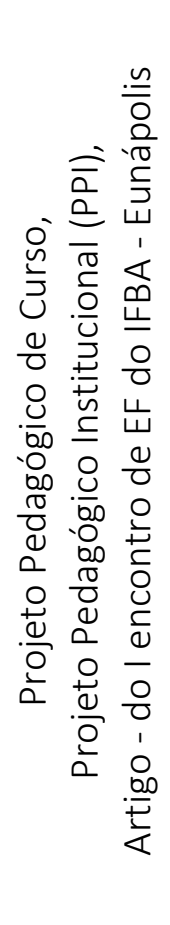 & 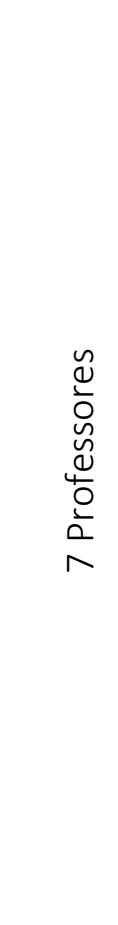 & $\begin{array}{l}\text { A autora destaca o pluralismo de ideias } \\
\text { pedagógicas indicados na organização } \\
\text { didática da instituição, voltadas para a } \\
\text { formação e comunicação operativa do } \\
\text { cidadão histórico-crítico e formação } \\
\text { humana, com foco no princípio educativo, } \\
\text { de modo a superar a dicotomia trabalho } \\
\text { manual/intelectual. } \\
\text { A autora referencia o uso, pelo coletivo } \\
\text { docente, do trabalho como categoria } \\
\text { ontológica da produção da existência } \\
\text { humana, como produção histórica, social e } \\
\text { cultural. De acordo com as análises, esse } \\
\text { tema contribui para a dimensão social e } \\
\text { possui conceitos ligados aos princípios } \\
\text { culturais, de modo a superar a visão } \\
\text { tecnicista do trabalho pedagógico da } \\
\text { Educação Física. }\end{array}$ \\
\hline 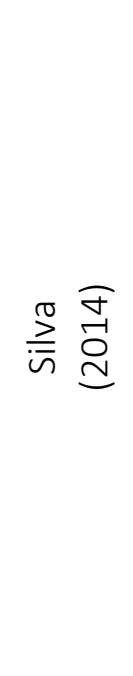 & $\begin{array}{l}\text { 1. A Educação Física no } \\
\text { currículo de Escolas } \\
\text { Profissionalizantes da } \\
\text { rede federal: uma } \\
\text { disciplina em processo } \\
\text { de "mutação" } \\
\text { Compreender o } \\
\text { 2. processo adaptativo da } \\
\text { Educação Física ao } \\
\text { currículo das Escolas } \\
\text { Profissionalizantes da } \\
\text { Rede Federal }\end{array}$ & 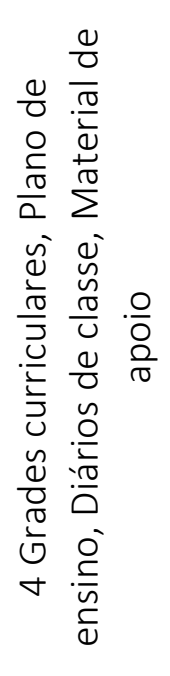 & 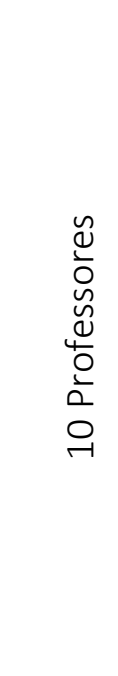 & $\begin{array}{l}\text { Constatou o engajamento dos docentes, } \\
\text { durante o processo histórico do ensino, na } \\
\text { tentativa de ruptura de concepções e } \\
\text { "mutações" de características arraigadas } \\
\text { no conteúdo esportivista, com uma } \\
\text { aproximação aos cuidados com a saúde do } \\
\text { trabalhador no ambiente de trabalho } \\
\text { (primeiros socorros ergonomia e educação } \\
\text { postural), aspectos que podem ser } \\
\text { direcionados aos cursos de ensino técnico } \\
\text { existentes na instituição. }\end{array}$ \\
\hline 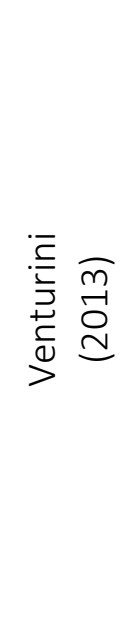 & $\begin{array}{l}\text { 1. Educação Profissional } \\
\text { e currículo em Educação } \\
\text { Física: memórias de uma } \\
\text { instituição centenária } \\
\text { 2. Levantar e conhecer } \\
\text { as memórs dos } \\
\text { professores da área de } \\
\text { Educação Física em seus } \\
\text { projetos } \\
\text { pedagógicos/currículos } \\
\text { no IFBA }\end{array}$ & 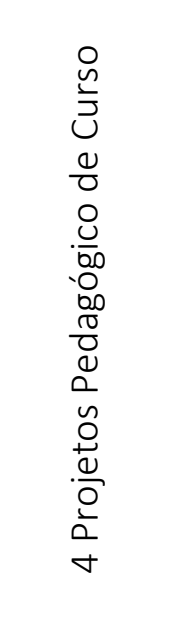 & 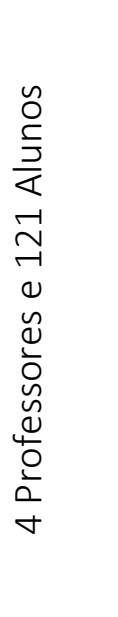 & $\begin{array}{l}\text { Sobre a integração curricular, a autora } \\
\text { apontou as motivações para o ensino dos } \\
\text { esportes e demais práticas esportivas, } \\
\text { como o trabalho de valores, formação do } \\
\text { cidadão crítico, superando os traços } \\
\text { históricos de hegemonia dessa prática } \\
\text { pautada pelas instituições médicas e } \\
\text { militares }\end{array}$ \\
\hline
\end{tabular}




\begin{tabular}{|c|c|c|c|}
\hline AUTOR & $\begin{array}{c}\text { 1. TítULO } \\
\text { 2. OBJETIVO }\end{array}$ & $\begin{array}{c}\text { DOCUMENTO* } \\
\text { AMOSTRA }\end{array}$ & $\begin{array}{c}\text { PRINCIPAIS RESULTADOS SOBRE } \\
\text { ENSINO MÉDIO INTEGRADO }\end{array}$ \\
\hline$*$ & $\begin{array}{c}\text { As amostras das pesquisas que não identificaram o número preciso de sujeito e/ou } \\
\text { documentos envolvidos nos estudos, foram apenas nomeados no quadro de } \\
\text { levantamento. }\end{array}$ \\
\hline
\end{tabular}

Conforme as informações da Quadro 2, os objetos de pesquisa recortados nas publicações podem ser divididos em: função da Educação Física (BATISTA et al., 2014; SAYÃO, 2019), finalidade e conteúdos no currículo (BOSCATTO; DARIDO, 2017), proposição de plano de unidade com base no referencial teórico-metodológico do materialismo histórico dialético (DIAS et al., 2016), elementos da Educação Física (METZNER et al., 2017), ensino da Educação Física (ANDREINI, 2018), ensino e professor (BERRIEL, 2017), professor de Educação Física (BERRIEL, 2017), saberes e práticas docentes (BOYNARD, 2015), contribuição da Educação Física (PASA, 2018), caracterização da Educação Física no currículo (SANTOS, 2016; SILVA, 2015; SÁ, 2019), planos de ensino (SOARES, 2017), história da Educação Física no currículo (SILVA, 2014; VENTURINI, 2013).

As publicações tomaram como instrumentos de coleta de dados, entrevistas, questionários, diários de aulas, registros de atividades (pesquisa, extensão e extracurriculares), artigo produzido por professores em Encontro de Educação Física; análises de documentos institucionais (Projetos Políticos de Curso, ementa de disciplina, plano de unidade), tendo com sujeitos das pesquisas os professores e os estudantes ou apenas os professores.

Serão discutidos nestes artigos principais desafios e perspectivas da Educação Física no Ensino Médio Integrado, identificados nas publicações, estruturados em categorias e subcategorias e classificados de acordo com as proximidades entre as propostas estabelecidas pelos autores. Esses desafios e perspectivas serão analisados, 
com a finalidade de indicar algumas vertentes para a integração da Educação Física e os cursos técnicos.

Após a exposição dos apontamentos evidenciados serão apresentados os desdobramentos e os possíveis diálogos entre duas categorias que ganharam destaque nas discussões: a "Ampliação/integração dos conteúdos da EF" - do eixo "Perspectivas da Educação Física para a integração curricular com o ensino técnico" - e a "Falta de integração dos saberes da Educação Física com a área técnica" - do eixo "Desafios da Educação Física para a Integração curricular com o ensino técnico". Também foram associadas a essas categorias as subcategorias "Falta de estrutura e condições para viabilizar as aulas de Educação Física" e "Formação Docente".

\subsection{DeSAFIOS DA EdUCAÇÃo FÍsICA PARA A INTEGRAÇão CURRICULAR COM O ENSINO TÉCNICO}

Os desafios identificados nas publicações podem ser observados conforme a Quadro 3.

Quadro 3: Desafios apontados pelos autores para integrar a Educação Física ao ensino técnico. Fonte: autoria própria.

\begin{tabular}{|c|c|c|}
\hline \multicolumn{3}{|c|}{ Desafios da Educação Física no Ensino Médio Integrado } \\
\hline CATEGORIA & SUBCATEGORIAS & AUTORES \\
\hline \multirow{2}{*}{ 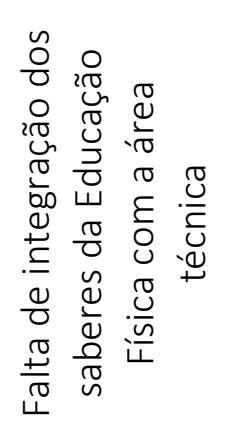 } & $\begin{array}{l}\text { Função da Educação Física no ensino } \\
\text { médio integrado }\end{array}$ & $\begin{array}{l}\text { (Boynard, 2015), } \\
\text { (Silva, 2015), } \\
\text { (Soares, 2017) }\end{array}$ \\
\hline & $\begin{array}{c}\text { Fragmentação e desvalorização dos } \\
\text { conteúdos da disciplina Educação } \\
\text { Física }\end{array}$ & $\begin{array}{c}\text { (Boscatto \& Darido, 2017), } \\
\text { (Santos, 2016), } \\
\text { (Silva, 2014), } \\
\text { (Sá, 2019), } \\
\text { (Venturini, 2013) }\end{array}$ \\
\hline
\end{tabular}




\begin{tabular}{|c|c|c|}
\hline 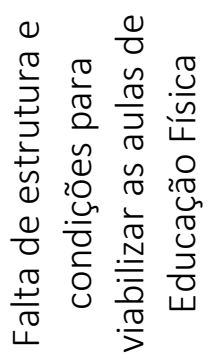 & $\begin{array}{l}\text { Estrutura física / material / } \\
\text { condições de trabalho }\end{array}$ & $\begin{array}{c}\text { (Andreini, 2018), } \\
\text { (Berriel, 2017) }\end{array}$ \\
\hline 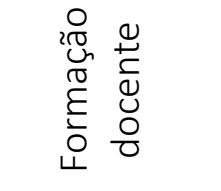 & $\begin{array}{c}\text { Ausência de discussão sobre ensino } \\
\text { médio integrado e formação } \\
\text { profissional }\end{array}$ & $\begin{array}{c}\text { (Andreini, 2018), } \\
\text { (Sá, 2019) }\end{array}$ \\
\hline
\end{tabular}

Os trabalhos caracterizados no desafio pela categoria "Falta de integração dos saberes da Educação Física com a área técnica" apresentaram como feições principais a necessidade de um maior aprofundamento sobre o entendimento correspondente à função da Educação Física e dos seus conteúdos no Ensino Médio Integrado. Tais carências são discutidas com mais detalhamento nas subcategorias: Função da Educação Física no ensino médio integrado (BOYNARD, 2015; SILVA, 2015; SOARES, 2017) e Fragmentação e desvalorização dos conteúdos da disciplina Educação Física (BOSCATTO \& DARIDO, 2017; SANTOS, 2016; SILVA, 2014; SÁ, 2019; VENTURINI, 2013).

Em relação as produções sobre Função da Educação Física no ensino médio integrado, todos os trabalhos identificaram que, embora existam referenciais e documentos de base que abordam características conceituais sobre os fazeres e saberes da Educação Física na escola, as práticas, em alguns campi, esbarram em escolhas pessoais ou dificuldades institucionais, que não favorecem planos de ação condizentes com os aportes teóricos.

As publicações referentes à subcategoria Fragmentação e desvalorização dos conteúdos da disciplina Educação Física relatam que, muitas vezes, a disciplina de Educação Física, na escola, aborda uma ampla gama de conteúdos que englobam variadas atividades corporais, que envolvem a área. Os autores, em geral, 
problematizam o fato de que, embora esses conteúdos incorporem as dimensões conceitual (o que se deve saber) procedimental (como se deve fazer) e atitudinal (o que esse conteúdo nos auxilia a ser); ainda há a predominância de aspectos instrumentais nas aulas. Isso decorre do fato de o foco recair sobre a a aptidão física e a habilidade técnica, quando comparados, por exemplo, aos aspectos que problematizam os elementos sociais, históricos e culturais que permeiam as atividades pela interação social, linguagem verbal e corporal.

É importante a Educação Física resgatar Bracht (2001), que nos ajuda a pensar que, para a preeminência do conhecimento científico da área na escola, é preciso se empenhar para uma maior flexibilização dos saberes adotados, para além do conhecimento conceitual, para que esse componente curricular possa se firmar no currículo, com base no reconhecimento da sua importância enquanto prática pedagógica.

O olhar reducionista no trato com a Educação Física pode levar à restrição da visão do aluno a um ser preocupado apenas em realizar o movimento, sem ponderar sobre o que está realizando. Santos (2016), por exemplo, pontua, em sua pesquisa, que é preciso melhorar a organização do trabalho pedagógico com uma compreensão do sujeito/corpo em uma visão ampliada, adotando a expressão corporal como linguagem e cultura, não se restringindo à visão biologicista.

Ao retratar o tipo de abordagem e as formas de trabalhar os conteúdos em aula com o Ensino Médio Integrado, Sá (2019) reforça a fragmentação percebida nos resultados sobre os conteúdos da cultura corporal,

[...] Os professores de EF buscam a legitimação do componente no currículo a partir do referencial da cultural corporal, porém as narrativas relevam algumas hibridizações desse conceito, manifestas pela continuidade da influência do currículo esportivista e do currículo saudável, em certos momentos. Essas acomodações colocam em xeque o potencial crítico da proposta à media que reforçam a colonização do currículo e sua submissão à concepção individualista de saúde. (SÁ, 2019, p. 198) 
As pesquisas anunciam diferentes justificativas para a não diferenciação entre conteúdos do ensino regular e do ensino técnico, bem como argumentam sobre a preservação da hegemonia dos conteúdos mais tradicionais da área.

Andreini (2018) sinalizou que existe o argumento de a Educação Física poder contribuir para as finalidades da Educação Profissional, sem perder os seus objetivos e especificidade. Além disso, a maior dificuldade está sinalizada pelo pouco conhecimento dos professores sobre a área técnica e como articular essa relação.

Na mesma direção, Silva (2014, p. 128) apontou a não existência de qualquer distinção entre "[...] as disciplinas de tradição propedêutica e as disciplinas de tradição profissionalizante". Ao que corresponde a reflexão sobre a diferenciação entre o que ensinar no ensino regular e no técnico Soares (2017) também pontuou que,

[...] Não há uma preocupação dos professores em oferecer conteúdos específicos que se relacionem diretamente com a formação do curso técnico ofertado. Os professores relataram que sempre aproximam as discussões das aulas com questões gerais da formação dos alunos, buscando articular os conhecimentos específicos da Educação Física com os de outras disciplinas, induzindo os alunos a reconhecer a importância do todo na sua formação. ( $p$. 148)

A falta de integração da Educação Física com a Educação Profissional, bem como os saberes ou conteúdos a serem trabalhados pela disciplina no ensino técnico, ainda podem ser apresentados por alguns autores com uma outra nuance de dificuldade diferente das já tratadas anteriormente. Há autores que associam a dificuldade da integração curricular como uma consequência do entendimento que o professor tem sobre o objetivo da Educação Física na Educação Profissional.

Outra dificuldade apontada nas publicações é a "Falta de estrutura e condições para viabilizar as aulas de Educação Física". Esse assunto é debatido com base nos materiais e espaços inadequados, utilizados em aula, muitas vezes ocasionando dificuldades no cumprimento do potencial da Educação Física no Ensino Médio Integrado. Além disso, afetam as situações de trabalho que envolvem os professores e 
dificultam a ação pedagógica de refletir sobre a integração curricular. Alguns trabalhos problematizam como subcategoria a "Estrutura física/material e condições de trabalho" (ANDREINI, 2018; BERRIEL, 2017).

Com a falta de materiais ou espaços físicos para as aulas, alguns professores precisam adaptar os recursos e criar alternativas de espaços para promover vivências dos conteúdos aos alunos. Isso gera consequências no planejamento e na definição de objetivos, afeta a integração e desenvolvimento das aulas. Dependendo do campus e do curso técnico integrado, podem existir inúmeras turmas de Ensino Médio Integrado. Consequentemente, a disciplina de Educação Física pode vir a ofertar um número elevado de aulas, bem como uma distribuição de aula desigual entre os anos do curso técnico. Existem cursos que apresentam aulas de Educação Física em todos os anos de ensino, outros não. Da mesma maneira, existem cursos com diferentes cargas horárias de Educação Física por ano, o que dificulta a unidade e a problematização da importância da disciplina nos respectivos cursos técnicos (ANDREINI, 2018).

Quando analisado o desafio "Formação docente", emerge a possibilidade de a prática do professor ser mergulhada em concepções e valores constituídos em suas formações iniciais e/ou continuada, as quais podem dificultar a compreensão e o trabalho docente no Instituto Federal pela categoria ausência de discussão sobre ensino médio integrado e formação profissional.

Sá (2019) frisa em sua pesquisa a urgência de mais investimentos das próreitorias de ensino e dos campi em desenvolver o currículo integrado, por meio da reformulação dos projetos políticos de curso, em produção coletiva, a fim de superar a concepção instrumental dos currículos. Defende, ainda, a necessidade de investimentos na formação de professores em acordo com os objetivos da Educação Profissional. 
Ambos os trabalhos retratam a necessidade da formação docente como um caminho para a promoção da integração, seja ela pelo viés da formação inicial (graduação) ou continuada (pós-graduação).

\subsection{Perspectivas da Educação Física para a IntegraçÃo CuRricular com o Ensino Técnico}

As perspectivas identificadas nas publicações podem ser observadas conforme a Quadro 4.

Quadro 4: Perspectivas apontadas pelos autores para a integrar a Educação Física ao ensino técnico. Fonte: autoria própria.

\begin{tabular}{|c|c|c|c|}
\hline \multicolumn{4}{|c|}{ Perspectivas da Educação Física no Ensino Médio Integrado } \\
\hline CATEGORIA & SUBCATEGORIAS & \multicolumn{2}{|l|}{ AUTORES } \\
\hline 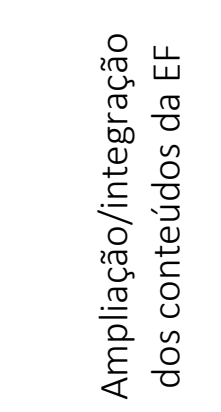 & $\begin{array}{c}\text { Ressignificação das concepções } \\
\text { / orientações teóricas } \\
\text { e/ou } \\
\text { diversificação e } \\
\text { problematização dos conteúdos }\end{array}$ & $\begin{array}{c}\text { (Andreini, 2018), } \\
\text { (Batista et al., 2014), } \\
\text { (Berriel, 2017), } \\
\text { (Boscatto \& Darido, 2017), } \\
\text { (Dias et al., 2016), } \\
\text { (Metzner et al., 2017), } \\
\text { (Santos, 2016), }\end{array}$ & $\begin{array}{c}\text { (Sayão, 2019), } \\
\text { (Silva, 2014), } \\
\text { (Silva, 2015), } \\
\text { (Soares, 2017), } \\
\text { (Sá, 2019), } \\
\text { (Pasa, 2018) }\end{array}$ \\
\hline 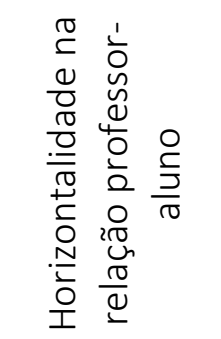 & $\begin{array}{l}\text { Participação coletiva na } \\
\text { construção das aulas do ensino } \\
\text { médio integrado }\end{array}$ & \multicolumn{2}{|c|}{$\begin{array}{c}\text { (Berriel, 2017), } \\
\text { (Metzner et al., 2017), } \\
\text { (Sá, 2019) }\end{array}$} \\
\hline 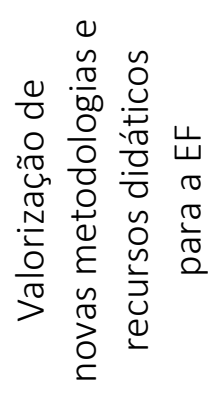 & $\begin{array}{c}\text { Projetos interligados com a } \\
\text { Educação Física }\end{array}$ & \multicolumn{2}{|c|}{$\begin{array}{l}\text { (Metzner et al., 2017) } \\
\text { (Santos, 2016), } \\
\text { (Sayão, 2019), } \\
\text { (Silva, 2015) }\end{array}$} \\
\hline
\end{tabular}


Os trabalhos apresentados na perspectiva "Ampliação/integração dos conteúdos da Educação Física" foram agrupados por expor as tentativas de se pensarem as possibilidades de promover o Ensino Médio Integrado por meio dos conteúdos da Educação Física. Para tanto, foram evidenciados na subcategoria Ressignificação das concepções/orientações teóricas e/ou diversificação e problematização dos conteúdos (ANDREINI, 2018; BATISTA et al., 2014; BERRIEL, 2017; BOSCATTO \& DARIDO, 2017; DIAS et al., 2016; METZNER et al., 2017; PASA, 2018; SÁ, 2019; SANTOS, 2016; SAYÃO, 2019; SILVA, 2014; SOARES, 2017).

Ao analisarmos as possibilidades enfatizadas nas publicações, todos os trabalhos mencionam enquanto referencial teórico, as concepções conceituais que perpassam pela formação crítica e integral dos alunos. Para tanto, utilizaram similaridade na escolha dos referenciais que discutem as percepções teóricas e os seus respectivos conteúdos de ensino para a Educação Física, sendo alguns dos autores citados (BARBIERI, 2001; BRACHT, 1999, 2003; BETTI, 1991, 2003; COLETIVO DE AUTORES, 2012; DAOLIO, 1995; KUNZ, 1991, 2004; GUEDES, 1994; HILDEBRANDT, 1986; NAHAS, 2013; MATOS \& NEIRA, 2000; MOREIRA, 1992; NEIRA, 2016; OLIVEIRA, 1985; PCN'S, 2000; TANI et al., 1988).

Nesse caminho, os trabalhos valorizam os resultados que possibilitem aos professores estimular o desenvolvimento dos alunos como cidadãos críticos, praticantes do lúdico, ativos, reflexivos, que considerem valores culturais (BATISTA et al., 2014, METZNER et al., 2017).

No mesmo trajeto, as referências devem estar pautadas "[...] em algumas tendências, como o construtivismo, saúde renovada, cultura corporal de movimento e a tendência critico-emancipatória (SILVA, 2015, p. 146)". Isso possibilita entender que a "[...] oferta não pode estar justificada apenas pelas orientações curriculares, mas pelo reconhecimento da área como campo de intervenção e construção do 
conhecimento (SOARES, 2017, p. 147)", que tem como papel social "[...] levar o sujeito a comunicar-se operativamente no mundo social da cultura e desenvolver a noção de historicidade da cultura corporal (SANTOS, 2016, p. 114)", e buscar a "[...] legitimidade do componente no currículo a partir do referencial da cultural (SÁ, 2019, p. 198)”.

Ainda nessa perspectiva, alguns trabalhos defendem que essa tendência gera uma consequência na (re)contextualização dos conteúdos. Para esses autores, é preciso recorrer às considerações epistemológicas da Educação Física como uma das condições para realizar a escolha e a sistematização dos conteúdos a serem utilizados nas aulas. Em argumento próximo a essas discussões, Libâneo, (2017, p.39), relata que

[...] os conteúdos são realidades exteriores ao aluno, que devem ser assimilados e não simplesmente reinventados, eles não são fechados e refratários às realidades sociais; não basta apenas que os conteúdos sejam ensinados, é necessário que se liguem de forma indissociável a sua significação humana e social.

Ao declarar que as teorias progressistas da Educação Física adotam os procedimentos didático-pedagógicos por meio de um olhar crítico, Bracht (1999) destaca que tais teorias problematizam as formas culturas do movimento humano, passando do simples olhar biológico ou mecânico, para a compreensão da dimensão histórico-cultural.

Alinhada com a Ressignificação das concepções/orientações teóricas, a Diversificação e problematização dos conteúdos, busca o caminho do rompimento com os conteúdos que predominam em uma única dimensão de ensino - seja o esporte ou outras atividades que proporcionem, exclusivamente, habilidades técnicas e/ou de rendimento - e da construção do exercício da autonomia, pautada em uma visão ampliada da Educação Física.

Todas as publicações que incluem essa categoria destacaram que, para refletir e redimensionar as orientações teóricas sobre a Educação Física e o seu papel com o Ensino Médio Integrado, com efeito, deve-se articular uma reestruturação dos 
planejamentos pedagógicos e uma problematização sobre os conteúdos. Além disso, todos os trabalhos tiverem como fonte de dados os documentos oficiais da instituição, além das informações coletadas com os professores.

Uma possibilidade exposta nas publicações, no caminho para a integração, foi o incentivo correspondente à categoria "Horizontalidade na relação professor-aluno". Esse tema está ligado às ações docentes, construídas no planejamento e na prática pedagógica, de maneira que os alunos alcancem uma melhor compreensão do que seja Ensino Médio Integrado. Para tal alcance, as pesquisas apontaram a subcategoria Participação coletiva na construção das aulas do ensino médio integrado (BERRIEL, 2017; METZNER et al., 2017; SÁ, 2019).

A coparticipação dos alunos em aula é proposta na pesquisa de Berriel (2017), como uma relação dialógica possível para a construção de um currículo integrado. Como destaca o autor, educar é mais complexo que seguir um currículo prescrito razão pela qual há a necessidade de considerar a cultura do estudante, o contexto que o circunda, seu curso, bem como o impacto que esses fatores geram na sua percepção.

Cabe salientar como presença em todos os trabalhos, que buscam como processo a participação coletiva na construção das aulas, a escuta e a colaboração dos alunos enquanto sujeitos do percurso.

A perspectiva "Valorização de novas metodologias e recursos didáticos para a EF" é abordada com o plano de ação/intervenção elaborado pelo professor, no campo pedagógico da área, para além do segmento de ensino. Tal situação pode ser efetivada, para alguns autores, pelo uso de projetos interligados com a Educação Física (METZNER et al., 2017; SAYÃO, 2019; SILVA, 2015; SÁ, 2019).

Entre os resultados, Metzner et al. (2017) destacam os dados referentes às ações pedagógicas que extrapolam o currículo mínimo e abarcam as práticas de pesquisa, extensão e projetos extracurriculares (eventos, jogos - internos e externos - gincanas), 
como propostas de integração curricular. Essas atividades enriquecem a formação do aluno pela contextualização em âmbito social, econômico, de base histórico-política e no campo do pensamento crítico-reflexivo, no caminho de uma formação expandida.

O aspecto da interdisicplinaridade é mencionado por Santos (2016), ao considerar o diálogo entre as diferentes áreas de conhecimento, bem como entre os professores de Educação Física. É apontada como uma possibilidade de construir mudanças no currículo integrado e deve estar atrelada à proposta pedagógica institucional, em aspectos inter/multi/transdisciplinar (com projetos integradores, seminários, fóruns de discussões, jogos, festivais de integração e aulas de campo). A autora menciona que a eficácia dos objetivos para a formação do currículo integrado, tanto nos projetos pedagógicos quanto nas ações dos docentes, se dará por meio da integração dos professores na sustentação da coerência com a formação omnilateral, durante a discussão de um projeto. Afirma ainda que essa possibilidade não constitui o todo de um currículo integrado, mas é considerado um passo para a formação emancipatória.

Dentro dessa mesma perspectiva, ainda existem variáveis sobre a inserção dos recursos e metodologias. A pesquisa trabalhada por Silva (2015) retrata uma nuance mais problematizadora ao ressaltar que, embora os projetos de pesquisa e extensão sejam uma possibilidade de promoção da integração curricular, pode haver ambiguidade na ação docente, pela não contextualização conceitual, bem como a não visualização de uma função destinada à Educação Física nos cursos técnicos. Santos (2016) relata que os docentes não apontam exemplos concretos de como seria integração em um projeto. Já os estudos que analisam os projetos interdisciplinares, destacam os usos dos trabalhos inter/multi e/ou transdisciplinar como possibilidade de integração. 
Todos os trabalhos mencionam como possibilidades metodológicas e didáticas para a integração curricular e trabalhos de natureza inter, multi e transdisciplinar, dentro do plano de ensino. Além disso, as publicações trazem como semelhança as sugestões de realizar a integração por meio de projetos de pesquisa e extensão.

\subsection{INTEGRAÇÃo CURRICULAR MEDIADA POR DISTANCIAMENTOS E APROXIMAÇÕES}

No contexto das especificações e apontamentos das publicações sobre o que seria considerado mais relevante para a Educação Física no Ensino Médio Integrado, há direcionamentos ligados aos aspectos relacionados ao papel da área, a aportes teóricos, conteúdos, metodologias e recursos didáticos, estruturas e condições de trabalho, relação professor-aluno e formação docente. Na tentativa de aprofundar a compreensão dos resultados e guiar os encaminhamentos da prática pedagógica da Educação Física nessa conjuntura, discutimos com detalhes, com base nas categorias apresentadas, o desafio e a perspectiva que teve maior frequência nos materiais analisados. O intuito de tal proposição foi dialogar com os resultados em busca da identificação de quais os motivos que podem levar um aspecto a ser considerado, ao mesmo tempo, uma possibilidade e uma dificuldade para a Educação Física realizar uma inserção no Ensino Médio Integrado. Em seguida, pontuamos as nuances presentes nos desafios "Falta de estrutura e condições para viabilizar as aulas de Educação Física" e "Formação docente" os quais levam a pensar a "política educacional", como um aspecto de fundo que delineia tais desafios.

Quando esses dados são relacionados e não apresentam circunstâncias positivas, pode haver dificuldades de se proporem aulas de Educação Física numa perspectiva de integração curricular.

Ao pensar na subcategoria "Falta de estrutura e condições para viabilizar as aulas de Educação Física", um elemento que sobressai em alguns dados é o da "política educacional", enquanto condição de trabalho. Nas análises ressaltadas pelos autores, 
foi percebida, nos documentos institucionais que discutem as matrizes curriculares, a tentativa de criar possibilidades concretas de integração entre ensino médio e técnico, por meio da inserção dos docentes na elaboração e/ou reestruturação de seus documentos.

Em termos de presença da Educação Física como componente curricular junto ao Ensino Médio Integrado, possivelmente, a revisão das formas de elaboração e reestruturação dos planos de ensino poderiam auxiliar na compreensão da Educação Física como área importante para a formação humana.

Ao que corresponde a categoria "formação docente", os autores das publicações em questão argumentam que problematizar a formação do professor e o papel da Educação Física, como área de intervenção que pode trabalhar o desenvolvimento ampliado dos educandos, possibilita planos de ação curriculares mais integradores.

Em discussões mais amplas sobre a formação docente, algumas referências na literatura corroboram a indicação de que a atuação profissional é desenhada pela formação profissional e as discussões geradas nesse processo (NÓVOA, 2019), mas também atravessada pelas experiências diárias, criadas e ressignificadas na prática docente, que geram recursos para criar ações mais organizadas (SACRISTAN, 1998). Nesse caso, considerar os alunos enquanto sujeitos participantes do processo se tornam importante no processo de pensar a formação e prática pedagógica.

Na mesma linha, Daolio (2004) argumenta sobre a forma como representamos os corpos na sociedade em que vivemos. Essa representação diz muito dos valores e princípios culturais que inserimos em nosso meio como referência. Nas aulas de Educação Física, não é diferente. Ao pensarmos a participação dos corpos/sujeitos no planejamento e prática pedagógica, é preciso considerar os sujeitos envolvidos naqueles ambientes como sujeitos da vida social, que possuem seus costumes, têm suas diferentes crenças e formas de pensar. É necessário, principalmente, considerar 
a singularidade de cada sujeito envolvido no ato educativo, de modo que, o que é representativo para um, pode não ser para o outro.

Nessa perspectiva, é importante o trabalho coletivo e com base em diferentes dimensões, conteúdos, concepções pedagógicas e metodologia de ensino. Os docentes envolvidos no processo pedagógico da disciplina, dotados de formações e experiências profissionais que não vão ao encontro de uma vertente ampliada possivelmente terão mais dificuldades de refletir sobre a Educação Física no Ensino Médio Integrado.

\section{CONSIDERAÇÕES FINAIS}

As pesquisas aqui estudadas apontam que, embora alguns trabalhos ressaltem o caráter crítico e humanístico da formação, as ações dos professores direcionam para perspectivas de caráter mais reducionista e a permanência, ainda, de alguns aspectos em detrimento de outros, muitas vezes, sem realizar reflexões sobre a importância e o valor daquele saber.

Diante das problematizações efetuadas, podemos considerar que as concepções teóricas e conteúdos existentes nos documentos institucionais e priorizadas nas práticas docentes podem possibilitar ou dificultar o movimento de integração curricular, dependendo dos caminhos e preferências - pessoais e profissionais escolhidos pelos professores. Em face disso, apontamos a formação docente e a metodologia de ensino como aspectos de comunicação direta para se pensar o ensino médio de forma integrada.

É importante recomendar, por exemplo, que a educação integral possa ser construída por diferentes metodologias, tais como os projetos interdisciplinares, os quais necessitam, também, fazer sentido para o aluno. Sem as condições pedagógicas condizentes, tais projetos perdem o significado. 
AGRADECIMENTOS

À Universidade Federal do Rio de Janeiro (UFRJ), ao Instituto Federal do Espírito Santo (IFES), à Universidade de Coimbra (UC), pelo apoio à pesquisa realizada.

O presente trabalho foi realizado com apoio da Coordenação de Aperfeiçoamento de Pessoal de Nível Superior - Brasil (CAPES) - Código de Financiamento 001. 


\section{REFERÊNCIAS}

Andreini, Fabiana. O ensino da Educação Física no Instituto Federal de São Paulo. 2018. Dissertação (Mestrado em Docência) - Faculdade de Ciências, Universidade Estadual Paulista, Bauru, 2018. Disponível em: http://hdl.handle.net/11449/153692. Acesso em: 22/12/2019.

BARBIERI, César Augustus Santos. Esporte educacional: uma possibilidade de restauração do humano no homem. Canoas: ULBRA, 2001.

BARDIN, Laurence. Análise de Conteúdo. São Paulo: Edições 70, 2018.

BATISTA, Alison Pereira; SOUZA FILHO, Moysés; OLIVEIRA, Ingrid Patrícia Barbosa de, SOUZA, Hunaway Albuquerque Galvão; MELO, José Pereira de. Possibilidades e desafios da Educação Física como componente curricular no processo de expansão regional do Instituto Federal De Educação, Ciência e Tecnologia do Rio Grande do Norte - IFRN. Holos, v.4, p. 492-501, 2014. Disponível em: https://doi.org/10.15628/holos.2014.2018. Acesso em: 27 dez. 2019.

BERRIEL, Rocindes de Souza. O professor de Educação Física na Educação Técnica Agrícola no Colégio Técnico da UFRRJ. 2017. Dissertação (Mestrado em Ciências), Universidade Federal Rural do Rio de Janeiro, Seropédica, 2017. Disponível em: https://tede.ufrrj.br/jspui/handle/jspui/2573. Acesso em: 22 dez. 2019.

BETTI, Mauro. Educação Física e sociedade. São Paulo: Movimento, 1991.

BETTI, Mauro. Educação Física escolar: do idealismo a pesquisa-ação. 2002. Tese (Livre-Docência em Métodos e Técnicas de Pesquisa em Educação Física e Motricidade Humana) - Faculdade de Ciências, Universidade Estadual Paulista, Bauru, $2003 a$.

BOSCATTO, Juliano Daniel; DARIDO, Suraya Cristina. A Educação Física no Ensino Médio Integrado a Educação Profissional e Tecnológica: percepções, curriculares. Pensar a Prática, v.20 n.1, p. 99-111, p 2017. Disponível em: https://doi.org/10.5216/rpp.v20i1.39029. Acesso em: 27 dez. 2019.

BOYNARD, Carlos Augusto Sanguedo. A prática pedagógica do docente da disciplina Educação Física no Instituto Federal Fluminense campus Centro: desvendando saberes e práticas. 2015. Dissertação (Mestrado em Ensino e na Saúde) - Escola de Enfermagem, Universidade Federal Fluminense, Niterói, 2015. Disponível em: https://app.uff.br/riuff/handle/1/2561. Acesso em: 22 dez. 2019.

BRACHT, Valter. A constituição das teorias pedagógicas da Educação Física. Cadernos Cedes, ano XIX, n. 48, p. 69-88, Agosto, 1999.

BRACHT, Valter. Saber e fazer pedagógicos: acerca da legitimidade da Educação Física como componente curricular. In CAPARRÓZ, Francisco. Eduardo. (Org.), Educação Física escolar: política, investigação e intervenção. Vitória: Proteoria, 2001. p. 66-80. 
BRACHT, Valter. Identidade e crise da Educação Física: um enfoque epistemológico. In BRACHT, Valter; CRISORIO, Ricardo (coords). A Educação Física no Brasil e na Argentina: identidade, desafios e perspectivas Campinas/SP: Autores Associados; Rio de Janeiro: PROSUL, 2003. p. 13-29.

BRASIL. Lei no 9.394, de 20 de dezembro de 1996. Estabelece as diretrizes e bases da educação nacional. Diário Oficial da União, [1996]. Disponível em: https://www2.camara.leg.br/legin/fed/lei/1996/lei-9394-20-dezembro-1996 362578norma-pl.html. Acesso em: 10 dez. 2019.

BRASIL. Ministério da Educação. Parâmetros Nacionais Curriculares Ensino Médio: bases legais, [2000]. Disponível em: http://portal.mec.gov.br/seb/arquivos/pdf/blegais.pdf. Acesso em 10 dez. 2019.

BRASIL. Decreto n‥ 5154, de 23 de julho de 2004. Regulamenta o $§ 20$ do art. 36 e os arts. 39 a 41 da Lei no 9.394, de 20 de dezembro de 1996, que estabelece as diretrizes e bases da educação nacional, e dá outras providências. Diário Oficial da União [2004]. Disponível em: https://www2.camara.leg.br/legin/fed/decret/2004/decreto-5154-23julho-2004-533121-publicacaooriginal-16200-pe.html. Acesso em: 10 dez. 2019.

BRASIL. Lei n.o 11.892 de 29 de dezembro de 2008. Institui a Rede Federal de Educação Profissional, Científica e Tecnológica, cria os Institutos Federais de Educação, Ciência e Tecnologia e dá outras providências. Diário Oficial da União, [2008]. Disponível em: https://www2.camara.leg.br/legin/fed/lei/2008/lei-11892-29-dezembro-2008-

585085-publicacaooriginal-108020-pl.html. Acesso em 10 dez. 2019.

BRASIL. Ministério da Educação. Diretrizes Curriculares Nacionais da Educação Básica. Secretaria de Educação Básica. Diretoria de Currículo e Educação Integral. MEC, SEB, DICEI. 562 p. [2012]. Disponível em: http://portal.mec.gov.br/docman/julho-2013pdf/13677-diretrizes-educacao-basica-2013-pdf/file. Acesso em: 10 dez. 2019.

COlETIVO DE AUTORES. Metodologia do Ensino de Educação Física. São Paulo: Cortez/Autores Associados, 2012.

CORDÃO, Francisco Aparecido; MORAES, Francisco de. Educação Profissional no Brasil: síntese histórica e perspectivas. São Paulo: Senac, 2017.

DAOLIO, Jocimar. Da cultura do corpo. Campinas: Papirus, 1995.

DAOLIO, Jocimar. Educação Física e o conceito de cultura: polêmicas do nosso tempo. Campinas: Autores Associados, 2004.

DIAS, Graziany Penna; FARIA, Miguel Fabiano de; SANTOS, Marcelo Silva dos; MACIEL, Thiago Barreto; FERNANDES, Silvio Anderson Toledo. Pedagogia histórico-crítica, cultura corporal, saúde e atividade física: aspectos teóricos e metodológicos para o ensino médio. Nuances: estudos sobre educação, v. 27 n. 1, p. 165-186, 2016. 
Disponível em: http://dx.doi.org/10.14572/nuances.v27i1.3958. Acesso em 27 dez. 2019.

FREIRE, João Batista. Educação de corpo inteiro. São Paulo: Scipione, 1994.

FREIRE, Paulo. Pedagogia da autonomia: saberes necessários à prática educativa. São Paulo: Paz e Terra, 2006.

FRIGOTTO, Gaudêncio. A relação da Educação Profissional e tecnológica com a universalização da educação básica. In MOLL, Jaqueline (Org.). Educação Profissional e Tecnológica no Brasil Contemporâneo: Desafios, Tensões e Possibilidades. Por Alegre: Artmed, 2010. p. 25-41.

GASPAROTTO Guilherme da Silva; NAVARRO Rodrigo Tramutolo. Tratamento e abordagens da Educação Física no Ensino Técnico em periódicos nacionais: o estado da arte. Revista Brasileira Ciência e Movimento, v.25 n.2, p. 154-165, 2017. Disponível em: http://dx.doi.org/10.18511/rbcm.v25i2.6305. Acesso em: 27 dez. 2019.

GUEDES, Dartagnan Pinto. Crescimento, composição corporal e desempenho motor em crianças e adolescentes do município de Londrina (PR), Brasil. 1994. Tese (Doutorado em Educação Física), Universidade de São Paulo, São Paulo, 1994. Disponível em: https://repositorio.usp.br/item/000739266. Acesso em: 28 fev. 2020.

HILDEBRANDT-STRAMANN, Reiner; LAGING, Ralf. Concepções abertas no Ensino da Educação Física. Rio de Janeiro: Ao Livro técnico, 1986.

KUNZ, Elenor. Educação Física: ensino e mudanças. Ijuí: Unijuí, 1991.

KUNZ, Elenor. Transformação didático-pedagógica do esporte. 5. ed. Ijuí: Unijuí, 2004.

LIBÂNEO, José Carlos. Didática. São Paulo: Cortez, 2017.

LOPES, Alice Casimiro. Políticas de integração curricular. Rio de Janeiro: EdUerj/Faperj, 2008.

MANFREDI, Silvia Maria. Educação Profissional no Brasil: atores e cenários ao longo da história. Jundiaí: Paco, 2017.

MEDEIROS, Tiago Nunes; BOSSLE, Cibel. Biehl; BOSSLE, Fabiano. A produção do conhecimento sobre a Educação Física nos currículos dos Institutos Federais de Educação, Ciência e Tecnologia. Holos, v.5, p. 01-20, 2019. Disponível em: https://doi.org/10.15628/holos.2019.8367. Acesso em: 27 dez. 2019.

MOURA, Dante Henrique. Ensino médio e Educação Profissional: dualidade histórica e possibilidades de integração. In Moll, Jaqueline (Org.). Educação Profissional e Tecnológica no Brasil Contemporâneo: Desafios, Tensões e Possibilidades. Porto Alegre: Artmed, 2010. p. 58-79. 
MATTOS, Mauro Gomes; NEIRA, Marcos Garcia. Educação Física na adolescência: construindo o conhecimento na escola. São Paulo: Phorte, 2000.

METZNER, Andreia Cristina; FERREIRA, Heidi Jancer; NUNES, Hudson Fabricius Peres, SO, Marcos Roberto; DRIGO, Alexandre Janotta. Contribuição da Educação Física para o Ensino Médio: estudo a partir da prática docente de professores de Institutos Federais. Motrivivência, v.29 n.52, p. 106-123, 2017. Disponível em: https://doi.org/10.5007/2175-8042.2017v29n52p106. Acesso em: 27 dez. 2019.

MOREIRA, Wagner Wey. Educação Física escolar: uma abordagem fenomenológica. Campinas: Editora da Unicamp, 1992.

NAHAS, Makus Vinicius. Atividade Física, Saúde e Qualidade de vida: conceitos e sugestões para um estilo de vida ativo. Londrina: Midiograf, 2013.

NEIRA, Marcos Garcia. Educação Física cultural: carta de navegação. Arquivos em Movimento, v.12 n.2, p. 82-103, 2016. Disponível em: https://revistas.ufrj.br/index.php/am/article/view/11149/pdf_78. Acesso em: 15 mar. 2020.

Nóvoa, António. Os professores e a sua formação num tempo de metamorfose da escola. Educação \& Realidade, v.44 n.3, p. 1-15, 2019. Disponível em: http://dx.doi.org/10.1590/2175-623684910. Acesso em: 10 fev. 2020.

OLIVEIRA, Vitor Marinho de. Educação Física humanista. Rio de Janeiro: Ao livro técnico, 1985.

PACHECO, Eliezer Moreira; CALDAS, Luiz; SOBRINHO, Moisés Domingos. Institutos Federais de educação, ciência e tecnologia: limites e possibilidades. In PACHECO, Eliezer Moreira; MORIGI, Valter. (Org.), Ensino técnico, formação profissional e cidadania: a revolução da Educação Profissional e tecnológica no Brasil. Porto Alegre: Tekne, 2012. p. 15-31.

PASA, Saulo Stevan. A contribuição da disciplina de Educação Física para a formação integral dos alunos. 2018. Dissertação (Mestrado em Educação) - Escola Superior de Educação, Instituto Politécnico do Porto, Porto. 2018. Disponível em: http://hdl.handle.net/10400.22/12735. Acesso em: 22 dez. 2019.

QUINTINO, Tânia Cristina de Assis; ROSA, Maria Inês Petrucci. Investigando relações entre currículo integrado e interdisciplinaridade numa história de formação continuada de professores do ensino médio da área de ciências. 2005, Bauru. Anais do V Encontro Nacional de Pesquisa em Educação em Ciências. Bauru: Unesp, 2005.

SÁ, Katia Regina de. Currículo do Ensino Médio Integrado do IFMG: a partitura, a polifonia e os solos da Educação Física. 2019. Tese (Doutorado em Educação) Faculdade de Educação, Universidade de São Paulo, São Paulo, 2019. Disponível em: https://doi.org/10.11606/T.48.2019.tde-23052019-172656. Acesso em: 22 dez. 2019. 
SACRISTÁN, José Gimeno. Plano do currículo, plano do ensino: o papel dos professores/as. In SACRISTÁN, José Gimeno; GÓMEZ, Angel Ignacio Pérez. Compreender e Transformar o Ensino. Porto Alegre: Artmed, 1998. p. 197-232.

Santos, Rosicler Teresinha Sauer. A Educação Física no currículo integrado do IFBA: realidades e possibilidades. 2016. Tese (Doutorado em Educação) - Faculdade de Educação, Universidade Federal da Bahia, Salvador, 2016. Disponível em: http://repositorio.ufba.br/ri/handle/ri/21075. Acesso em: 22 dez. 2019.

SAYÃO, Marcelo Nunes. A Educação Física na Educação Profissional: sentidos em disputa no Instituto Federal de Educação, Ciência e Tecnologia do Rio de Janeiro - IFRJ. Arquivos em movimento, v.15 n.1, p. 283-297, 2019. Disponível em: https://revistas.ufrj.br/index.php/am/article/view/21543/pdf. Acesso em: 27 dez. 2019.

SILVA, Eduardo Marczwski da. A Educação Física no currículo de Escolas Profissionalizantes da Rede Federal: uma disciplina em processo de "mutação". 2014. Tese (Doutorado em Ciências do Movimento Humano) - Escola de Educação Física, Universidade Federal do Rio Grande do Sul, Porto Alegre, 2014. Disponível em: http://hdl.handle.net/10183/99037. Acesso em: 22 dez. 2019.

SILVA, Tiago Amaral. A Educação Física no contexto dos cursos de Educação Profissional técnica de nível médio integrado do Instituto Federal de Educação, Ciência e Tecnologia de Mato Grosso do Sul. 2015. Dissertação (Mestrado em Educação) - Universidade Estadual do Oeste do Paraná, Cascavel, 2015. Disponível em: http://tede.unioeste.br/handle/tede/3300. Acesso em: 22 dez. 2019.

SILVA, Marlon André da; SILVA, Lisandra Oliveira e; NETO, Vicente Molina. Possibilidades da Educação Física no Ensino Médio Técnico. Movimento, v.22 n.1, p. 325-336, 2016. Disponível em: https://doi.org/10.22456/1982-8918.54333. Acesso em: 27 dez. 2019.

SOARES, Fernanda Cristina Merisio Fernandes. O currículo prescrito da Educação Física num contexto de ensino médio integrado. 2017. Dissertação (Mestrado em Educação Física) - Centro de Educação Física e Desporto, Universidade Federal do Espírito Santo, Vitória, 2017. Disponível em: http://repositorio.ufes.br/handle/10/7192. Acesso em: 22 dez. 2019.

TANI, Go. Educação Física escolar: fundamentos para uma abordagem desenvolvimentista. São Paulo: EPU/Edusp, 1988.

VENTURINI, Micheli. Educação Profissional e currículo em Educação Física: memórias de uma instituição centenária. 2013. Tese (Doutorado em Educação) - Faculdade de Educação, Universidade Federal da Bahia, Salvador, 2013. Disponível em: https://repositorio.ufba.br/ri/handle/ri/30049. Acesso em: 21 dez. 2019. 